\title{
Systematic review of the relationship of Helicobacter pylori infection with geographical latitude, average annual temperature and average daily sunshine
}

Chao $\mathrm{Lu}^{1+}$, Ye Yu${ }^{2+}$, Lan $\mathrm{Li}^{1}$, Chaohui $\mathrm{Yu}^{1}$ and Ping $\mathrm{Xu}^{{ }^{1 *}}$

\begin{abstract}
Background: Helicobacter pylori (H. pylori) infection is a worldwide threat to human health with high prevalence. In this study, we analyzed the relationship between latitude, average annual temperature, average daily sunshine time and H. pylori infection.

Methods: The PubMed, ClinicalTrials.gov, EBSCO and Web of Science databases were searched to identify studies reporting $\mathrm{H}$. pylori infection. Latitude $30^{\circ}$ was the cut-off level for low and mid-latitude areas. We obtained information for latitude, average annual temperature, average daily sunshine, and Human Development Index (HDI) from reports of studies of the relationships with H. pylori infection.

Results: Of the 51 studies included, there was significant difference in $\mathrm{H}$. pylori infection between the low- and midlatitude areas $(P=0.05)$. There was no significant difference in the prevalence of $H$. pylori infection in each $15^{\circ}$-latitude zone analyzed $(P=0.061)$. Subgroup analysis revealed the highest and lowest $H$. pylori infection rates in the developing regions at $>30^{\circ}$ latitude subgroup and the developed regions at $<30^{\circ}$ latitude subgroup, respectively $(P<0.001)$. Multivariate analysis showed that average annual temperature, average daily sunshine time and HDI were significantly correlated with $H$. pylori infection $(P=0.009, P<0.001, P<0.001$ ), while there was no correlation between $H$. pylori infection and latitude.

Conclusions: Our analysis showed that higher average annual temperature was associated with lower $H$. pylori infection rates, while average daily sunshine time correlated positively with $\mathrm{H}$. pylori infection. $\mathrm{HDI}$ was also found to be a significant factor, with higher $\mathrm{HDI}$ associated with lower infection rates. These findings provide evidence that can be used to devise strategies for the prevention and control of H. pylori.
\end{abstract}

Keywords: Latitude, Temperature, Sunshine, Helicobacter pylori

\section{Background}

Helicobacter pylori (H. pylori) is a Gram-negative microaerophilic bacterium that dwells in human gastric mucosa, causing stomach injury. H. pylori infection is commonly associated with gastroduodenal diseases in humans, such as chronic gastritis and peptic ulcers [1], gastric mucosa-associated lymphoid tissue lymphoma

\footnotetext{
* Correspondence: ymsego@zju.edu.cn

${ }^{\dagger}$ Equal contributors

'Department of Gastroenterology, the First Affiliated Hospital, College of Medicine, Zhejiang University, No. 79 Qingchun Road, Hangzhou 310003, China

Full list of author information is available at the end of the article
}

[2], and even gastric cancer [3,4]. Almost $50 \%$ of the human population worldwide is infected, with a higher rate in people living in developing countries [5]. A large number of studies have provided evidence of $H$. pylori in dental plaques, houseflies, human and animal feces, and natural environmental waters [6]. Therefore, water supplies contaminated by sewage containing fluids or feces from infected people have been considered to be a potential route of $H$. pylori transmission [6]. Several factors may contribute to $H$. pylori infection, such as socioeconomic status and living conditions [7], metabolic syndrome [8], sex [9], education and smoking [10].

(C) The Author(s). 2018 Open Access This article is distributed under the terms of the Creative Commons Attribution 4.0 International License (http://creativecommons.org/licenses/by/4.0/), which permits unrestricted use, distribution, and 
Among these factors, socioeconomic conditions play an important role in $H$. pylori infection. Our previous analysis of the Human Development Index (HDI) confirmed that high $H$. pylori recurrence rates are more likely in less-developed areas [7]. Thus, prevention and therapy of $H$. pylori have become a public health challenge.

There is clear geographic variation in the prevalence of H. pylori infection [11, 12]. Furthermore, vitamin D and vitamin $\mathrm{D}$ receptor (VDR) play an important protective role in H. pylori infection [13]. Vitamin D is an immunoregulatory agent widely known to mediate bone metabolism and plays a key role in target tissues, such as the kidney, thyroid, intestine, skin, immune cells, nonparenchymal hepatocytes, and biliary epithelial cells [14, 15]. Vitamin D synthesis depends on exposure to sunlight and solar ultraviolet radiation, which is affected by latitude, season, temperature and duration of daily sunshine [16]. Therefore, we hypothesized that the prevalence of $H$. pylori infection varies with changes in geographic areas (different latitudes, temperature and average daily sunshine time) that are associated with differences in the rates of vitamin D synthesis.

The purpose of this study was to determine the influence of different latitudes, temperature, HDI and average daily sunshine time on $H$. pylori infection rates. This information will highlight a novel epidemiologic and global perspective of $H$. pylori infection.

\section{Methods}

\section{Search strategy and study selection}

We searched articles published from January 1, 2000 to December 1, 2016 in the PubMed, ClinicalTrials.gov, EMBASE and Web of Science databases using the following search terms: (Helicobacter pylori OR H. pylori OR Helicobacter infection OR Helicobacter* OR HP OR Helicobacter pylori (MeSH)), and (infection OR infectious $(\mathrm{MeSH})$ ). Our study was limited to humans only and studies involving participants undergoing physical examination were included. People with digestive disease, such as gastritis, peptic ulcer, and stomach cancer, were excluded if they underwent physical examination. In addition, we focused on studies with participants aged over 18 years. Age, sex, smoking, HDI and other confounding factors were also considered. Eligibility was evaluated by two investigators independently. The quality of papers was assessed using the Strengthening the Reporting of Observational studies in Epidemiology (STROBE) checklist [17]. Any study-related disagreements were resolved by a third reviewer.

\section{Definitions}

\section{Diagnostic methods for $\mathrm{H}$. pylori infection}

Combining the guidelines [18] and previous metaanalysis [19], a diagnosis of $H$. pylori infection was confirmed on the basis of at least one positive result from the following tests: (1) ${ }^{13} \mathrm{C} /{ }^{14} \mathrm{C}$ urea breath test (UBT); (2) rapid urease test (RUT); (3) H. pylori culture; (4) stool antigen test; or (5) histology of biopsy staining. Because many medical centers used a serologic test for physical examination, serologic tests were also used to confirm diagnosis.

\section{Average daily sunshine time, latitude, temperature and HDI} After identification of the geographical location of the city or area participating in the study, we used the Hong Kong Observatory (http://gb.weather.gov.hk/contentc.htm) to obtain information for calculation of the average daily sunshine time and the average daily temperature of every city included in this study. The average daily sunshine time was calculated according to the following equation:

Average daily sunshine time $=$ annual average sunshine time/365; Annual average temperature was used in the analysis.

HDI was chosen to assess the socioeconomic status at the national level. This index is a measure of three basic dimensions of human development: health index (according to life expectancy at birth), education index (according to mean and expected years of schooling), and decent standard of living (gross national income per capita) [7]. The HDI data (1990-2012) is available on the United Nations Development Programme website (http://hdr.undp.org/en/reports/). Countries with a high HDI score (0.788 or higher) are regarded as developed, while others are defined as developing according to the United Nations [20].

\section{Data abstraction}

Data were extracted to Microsoft Excel (2007 edition; Microsoft, Redmond, WA, USA) for effective organization. The following data were obtained from included studies: the study area, latitude, average annual temperature and average daily sunshine duration (according to study area or country), year of study, participant number, diagnostic method used for H. pylori infection, HDI levels (according to study country in the relevant years), age, sex, and smoking.

We excluded papers without information for latitude, average annual temperature or average daily sunshine time. All data were double-checked by two authors.

\section{Statistical analysis}

The data obtained in this study exhibited normal distribution; therefore, Student's $t$-test was used to compare numerical variables for each latitude zone and different HDI zones. One-way analysis of variance (ANOVA) was performed to compare multiple groups and analysis of covariance (ANCOVA) was performed to analyze influence effects. Pair-wise comparisons of multiple groups 
were performed with Bonferroni Correction [21] if necessary. In the multivariate analysis, stepwise linear regression analysis was used to correlate $H$. pylori infection with HDI, latitude, average annual temperature and average daily sunshine time. Adjustment and discretization of different variables were conducted if necessary. Moreover, the potential of sex, age and smoking as influencing factors was analyzed in a randomized controlled model $\left(I^{2}>50 \%\right)$ or a fixed controlled model $\left(I^{2} \leq 50 \%\right)$ to compare differences between infected and non-infected individuals. In the multivariate analysis, $P \leq 0.05$ was considered to indicate a significant correlation and $0.1>P>0.05$ was considered to indicate a suggestive correlation. For other statistical methods, $P \leq 0.05$ was considered to indicate statistical significance. All statistical analysis was performed using SPSS 17.0 (IBM, Chicago, IL, USA). Associated data were calculated and plotted using GraphPad Prism 5 (Graph Pad, San Diego, CA, USA). The randomized controlled model was performed using Stata 12.0 (StataCorp, College Station, TX, USA).

\section{Results}

\section{Study selection}

Fifty-one studies originating from 58 regions were included in our final analysis (Fig. 1). Primary data and results for author, study area, HDI, latitude, average annual temperature, and average daily sunshine time are listed in Table 1. Geographically, studies originated mainly from Asia (25/58), Europe (19/58), America (11/58), Africa $(2 / 58)$ and Oceania $(1 / 58)$. In addition, according to the dichotomy of HDI, additional studies were included from developed countries (32/58) and developing countries (26/58). The cut-off level between the low and mid-latitude was set at $30^{\circ}$ latitude. Based on latitude, 13 studies originated from low latitude zones, and 45 from zones $30^{\circ}$ latitude and higher. Statistically significant heterogeneity was observed among all studies in this analysis.

\section{Prevalence of $H$. pylori infection}

The overall prevalence of $H$. pylori infection was 49 . $73 \% \pm 20.68 \%$, with a significant difference in the prevalence of $H$. pylori infection between the latitude zones $<30^{\circ}$ and $\geq 30^{\circ} \quad(39.92 \% \pm 21.15 \%$ vs. $52.56 \% \pm$ $19.88 \%, P=0.05$ ) (Fig. 2a). We further analyzed the prevalence of $H$. pylori infection in every $15^{\circ}$-latitude zone. The $H$. pylori infection rate was $35.43 \% \pm 24$. $68 \%\left(0-15^{\circ}\right), 43.77 \% \pm 18.71 \%\left(15-30^{\circ}\right), 56.29 \% \pm 17$. $24 \%\left(30-45^{\circ}\right)$, and $45.10 \% \pm 23.18 \%\left(\geq 45^{\circ}\right)$, respectively. ANOVA did not show a significant difference in the prevalence of $H$. pylori infection for each latitude zone $(P=0.061)$. However, we observed a rising trend in the prevalence of $H$. pylori infection from latitude $0^{\circ}$ to $45^{\circ}$ (Fig. 2b). Most of the regions in the latitude $\geq 45^{\circ}$ zones are developed areas; therefore, we used ANCOVA to assess the existence of confounding effects caused by the HDI. The results showed a linear relationship between HDI and latitude $(\mathrm{F}=22.328$, $P<0.001)$ and HDI affected the result of latitude as a confounding factor $(P=0.001)$. We then conducted a subgroup analysis. In the developing and developed regions, we also observed a similar rising trend in the prevalence of $H$. pylori infection from latitude 0 to

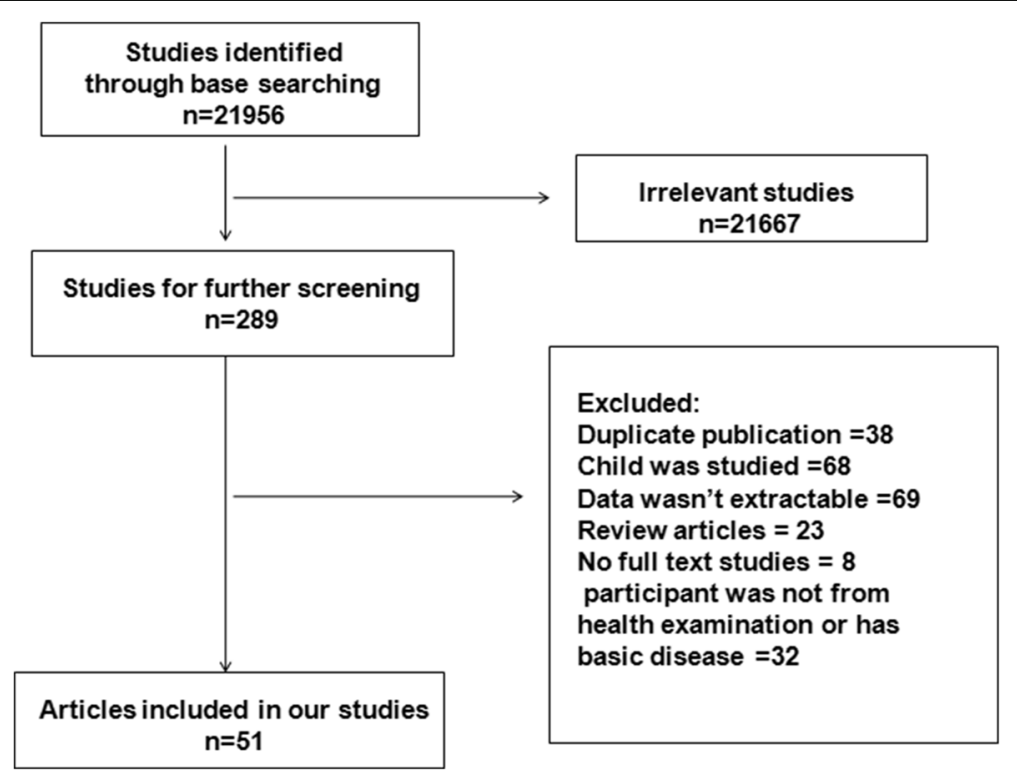

Fig. 1 Flow diagram of search strategy and study criteria 
Table 1 The basic characteristics of included papers

\begin{tabular}{|c|c|c|c|c|c|c|c|}
\hline Region & Author & Number (n) & Positive rate & Latitude $\left(^{\circ}\right)$ & Temperature $\left({ }^{\circ} \mathrm{C}\right)$ & Sunshine (h) & $\mathrm{HDI}$ \\
\hline \multicolumn{8}{|l|}{ Europe } \\
\hline Israel & Niv & 2128 & 0.328 & 31.00 & 9.31 & 16.45 & 0.872 \\
\hline Nottingham & Jackson & 2437 & 0.264 & 52.56 & 3.77 & 9.80 & 0.768 \\
\hline Lebanon & Naja & 308 & 0.520 & 33.45 & 8.05 & 20.87 & 0.761 \\
\hline Berlin & Berg & 1806 & 0.392 & 52.30 & 4.45 & 8.88 & 0.801 \\
\hline Rome & Gasbarrini & 655 & 0.400 & 41.80 & 6.77 & 15.20 & 0.825 \\
\hline Leeds & Moayyedi & 8429 & 0.276 & 53.48 & 3.36 & 8.76 & 0.818 \\
\hline Magdeburg & Wex & 2318 & 0.444 & 52.80 & 4.45 & 8.75 & 0.906 \\
\hline Novosibirsk & Reshetnikov & 438 & 0.884 & 55.20 & 6.03 & 1.73 & 0.723 \\
\hline Prague & Bures & 1406 & 0.292 & 50.05 & 4.57 & 7.85 & 0.867 \\
\hline Loiano & Bazzoli & 1533 & 0.679 & 44.16 & 5.59 & 8.60 & 0.803 \\
\hline Stockholm & Sorberg & 3502 & 0.177 & 59.19 & 4.99 & 6.63 & 0.855 \\
\hline Wroclaw & Iwanczak & 3307 & 0.842 & 51.10 & 4.10 & 8.32 & 0.794 \\
\hline Tbilisi & Kretsinger & 125 & 0.719 & 41.70 & 5.63 & 13.00 & 0.690 \\
\hline Heidelberg & Michel & 1797 & 0.481 & 49.25 & 4.49 & 11.50 & 0.916 \\
\hline Bratislava & Kuzela & 1838 & 0.351 & 48.08 & 5.58 & 10.50 & 0.836 \\
\hline Tirana & Monno & 1088 & 0.707 & 41.19 & 6.97 & 15.20 & 0.682 \\
\hline Reykjavik & Thjodleifsson & 447 & 0.363 & 64.08 & 3.48 & 4.30 & 0.859 \\
\hline Uppsala & Thjodleifsson & 359 & 0.112 & 59.51 & 4.86 & 6.50 & 0.897 \\
\hline Tartu & Thjodleifsson & 240 & 0.692 & 58.23 & 4.59 & 4.84 & 0.780 \\
\hline \multicolumn{8}{|l|}{ Asia } \\
\hline Beijing & Zhang & 2006 & 0.833 & 40.15 & 7.52 & 11.80 & 0.645 \\
\hline Ankara & Akin & 1089 & 0.774 & 39.52 & 6.71 & 11.71 & 0.653 \\
\hline Korea & Yim & 13,697 & 0.586 & 36.00 & 5.77 & 11.82 & 0.853 \\
\hline Okinawa & Toyoda & 1540 & 0.599 & 26.50 & 5.15 & 22.42 & 0.871 \\
\hline Malaysia & Goh & 2381 & 0.359 & 4.00 & 6.11 & 26.73 & 0.727 \\
\hline Islamabad & Rasheed & 205 & 0.819 & 33.43 & 8.07 & 21.34 & 0.522 \\
\hline Yangzhong & Zhu & 5417 & 0.634 & 32.19 & 5.85 & 15.10 & 0.699 \\
\hline North Sulawesi & Miftahussurur & 251 & 0.143 & 1.29 & 6.00 & 27.72 & 0.684 \\
\hline Arak & Afsharipour & 525 & 0.742 & 34.10 & 8.09 & 13.65 & 0.751 \\
\hline Nahavand & Alizadeh & 1518 & 0.710 & 34.11 & 7.55 & 10.83 & 0.735 \\
\hline Penang & Sasidharan & 5370 & 0.142 & 5.24 & 6.75 & 27.00 & 0.723 \\
\hline Tehran & Nouraie & 2326 & 0.690 & 35.40 & 8.25 & 17.00 & 0.703 \\
\hline Seoul & Kim & 1485 & 0.649 & 37.33 & 5.77 & 11.82 & 0.853 \\
\hline Kota Bharu & Rahim & 480 & 0.190 & 6.90 & 6.94 & 26.73 & 0.769 \\
\hline Hsinchu & Chen & 3578 & 0.202 & 24.81 & 5.07 & 22.60 & 0.882 \\
\hline Xiangshui & Shi & 1371 & 0.620 & 34.20 & 6.57 & 15.79 & 0.641 \\
\hline Korea & Lim & 10,796 & 0.545 & 36.00 & 5.77 & 11.82 & 0.891 \\
\hline Beijing & Cheng & 1232 & 0.468 & 40.15 & 7.52 & 11.80 & 0.812 \\
\hline Hangzhou & $\mathrm{Xu}$ & 8820 & 0.438 & 30.30 & 5.42 & 15.79 & 0.723 \\
\hline Hokkaido & Ueda & 1428 & 0.294 & 43.14 & 4.94 & 8.22 & 0.890 \\
\hline Aomori & Ueda & 782 & 0.497 & 40.49 & 4.64 & 9.73 & 0.890 \\
\hline Yamagata & Ueda & 3615 & 0.545 & 38.30 & 4.56 & 11.19 & 0.890 \\
\hline
\end{tabular}


Table 1 The basic characteristics of included papers (Continued)

\begin{tabular}{|c|c|c|c|c|c|c|c|}
\hline Region & Author & Number (n) & Positive rate & Latitude $\left({ }^{\circ}\right)$ & Temperature $\left({ }^{\circ} \mathrm{C}\right)$ & Sunshine (h) & $\overline{\mathrm{HDI}}$ \\
\hline Gunma & Ueda & 4914 & 0.323 & 36.40 & 5.42 & 13.91 & 0.890 \\
\hline Aichi & Ueda & 2237 & 0.306 & 35.10 & 5.58 & 15.04 & 0.890 \\
\hline Kagawa & Ueda & 442 & 0.378 & 34.30 & 5.80 & 15.35 & 0.890 \\
\hline \multicolumn{8}{|l|}{ America } \\
\hline America & Everhart & 7465 & 0.325 & 36.09 & 7.07 & 15.06 & 0.859 \\
\hline Nashville & Epplein & 310 & 0.787 & 36.09 & 6.88 & 15.06 & 0.888 \\
\hline Seattle & loannou & 6724 & 0.535 & 47.38 & 5.95 & 11.13 & 0.859 \\
\hline Ontario & Naja & 1306 & 0.294 & 43.40 & 5.58 & 7.16 & 0.896 \\
\hline Aklavik & Cheung & 194 & 0.660 & 68.13 & 3.54 & -8.20 & 0.896 \\
\hline Nassau & Carter & 204 & 0.578 & 24.15 & 7.91 & 24.85 & 0.778 \\
\hline São Paulo & Zaterka & 993 & 0.657 & 23.33 & 5.49 & 19.20 & 0.720 \\
\hline Guadeloupe & Weill & 854 & 0.552 & 16.15 & 7.60 & 26.30 & 0.848 \\
\hline São Paulo & Oba-Shinjo & 942 & 0.484 & 23.33 & 4.75 & 19.26 & 0.688 \\
\hline Recife & Melo & 405 & 0.314 & 8.30 & 6.75 & 25.46 & 0.683 \\
\hline Pelotas & Santos & 359 & 0.644 & 31.46 & 6.14 & 17.50 & 0.709 \\
\hline \multicolumn{8}{|l|}{ Africa } \\
\hline Belgium & Aguemon & 446 & 0.740 & 6.21 & 6.44 & 27.22 & 0.413 \\
\hline Tunis & Mansour & 250 & 0.632 & 36.48 & 7.69 & 20.00 & 0.689 \\
\hline \multicolumn{8}{|l|}{ Oceania } \\
\hline Queensland & Pandeya & 1316 & 0.230 & 27.30 & 7.50 & 21.40 & 0.904 \\
\hline
\end{tabular}
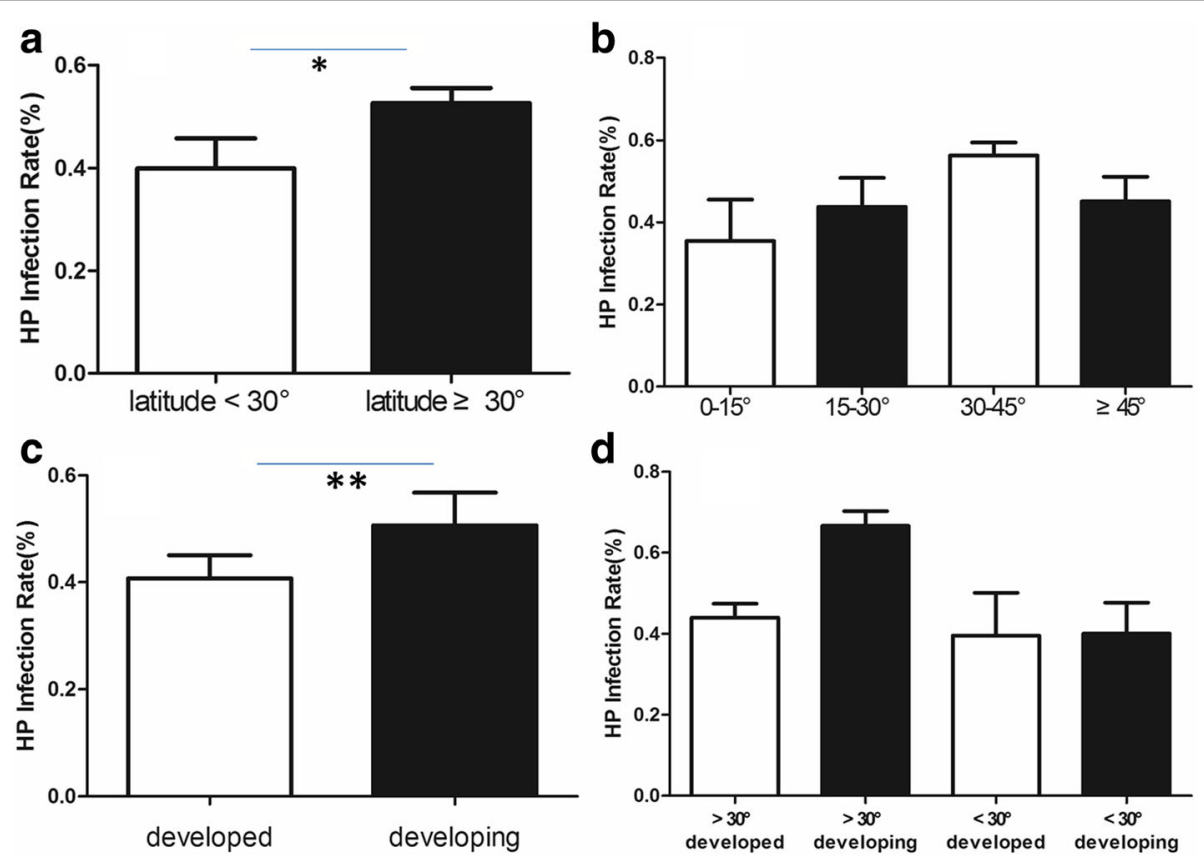

Fig. 2 a Comparison of the prevalence of Helicobacter pylori infection between low and mid-to-high latitude zones (39.92\% $\pm 21.15 \%$ vs. 52.56\% $\pm 19.88 \%$, $\left.{ }^{*} P=0.05\right)$; $\mathbf{b}$ Comparisons of the prevalence of $\mathrm{H}$. pylori infection in each $15^{\circ}$-latitude zone; $\mathbf{c}$ Comparison of the prevalence of $\mathrm{H}$. pylori infection between developed and developing regions ( $43.48 \% \pm 17.73 \%$ vs. $57.42 \% \pm 21.76 \%$, $\left.{ }^{* *} P=0.009\right)$; d Comparisons of the prevalence of $H$. pylori infection in developed countries and mid-to-high latitude zones, developing countries and mid-to-high latitude zones, developed countries and low latitude, developing countries and low latitude zones $(P<0.001)$ 

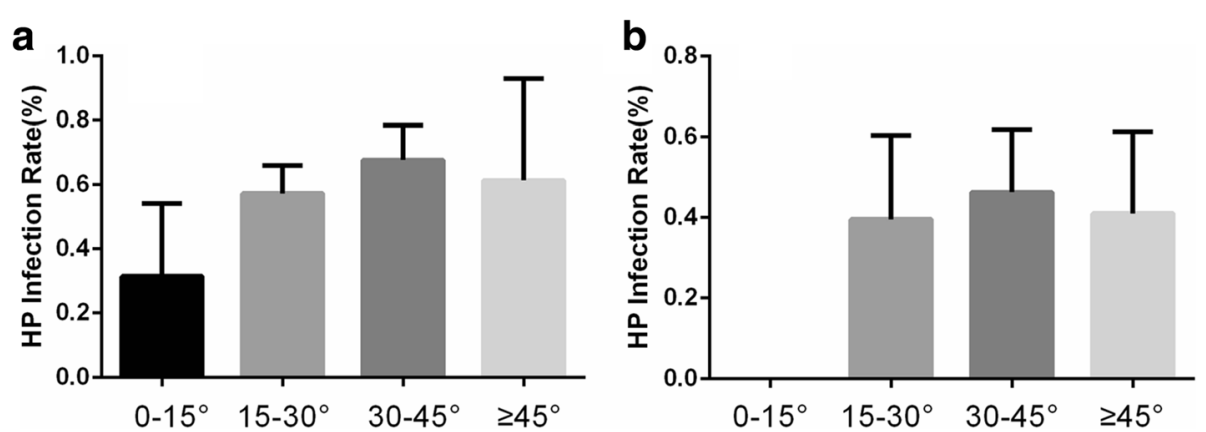

Fig. 3 a Comparisons of the prevalence of Helicobacter pylori infection for every $15^{\circ}$-latitude zone in developing regions; $\mathbf{b}$ Comparisons of the prevalence of $\mathrm{H}$. pylori infection for every $15^{\circ}$-latitude zone in developed regions

$45^{\circ}$ (Fig. 3a and b). We also divided regions into developed and developing regions according to the HDI. Individuals living in developed regions showed a lower infection rate than those in the developing regions $(43.48 \% \pm 17.73 \%$ vs. $57.42 \pm 21.76 \%, P=0.009)$ (Fig. 2c). To further confirm the relationship between HDI, latitude and $H$. pylori infection, we determined $H$. pylori infection rates in the following four groups of areas: I): $44.03 \% \pm 17.60 \%$ (developed countries \& $>30^{\circ}$ latitude); II): $66.60 \% \pm 15.08 \%$ (developing countries $\&>30^{\circ}$ latitude); III): $39.58 \% \pm 20.88 \%$ (developed countries \& $<30^{\circ}$ latitude); and IV): $40.08 \% \pm 22.53 \%$ (developing countries $\&<30^{\circ}$ latitude) (Fig. $2 \mathrm{~d}$ ); there were significant differences between each group $(P<0.001)$. The H. pylori infection rate was highest in developing regions at $>30^{\circ}$ latitude, while the rate was lowest in developed regions at $<30^{\circ}$ latitude. This indicated that low latitude regions with high $\mathrm{HDI}$ is protective against $H$. pylori infection.

Stepwise linear regression analysis revealed that HDI was significantly correlated with the prevalence of $H$. pylori infection (coefficient $=-0.556, P<0.001$ ). Furthermore, higher average annual temperature correlated with lower infection rates (coefficient $=-0.577, P<0.001$ ) and higher average daily sunshine time correlated with higher H. pylori infection rates (coefficient $=0.342, P=0.009$ ). However, there was no significant correlation between the prevalence of $H$. pylori infection and latitude. In European regions, we found that only HDI affected the prevalence of $H$. pylori infection (coefficient $=-0.648, P=0.003$ ), while the prevalence in Asian regions was affected by both HDI (coefficient $=-0.584, P<0.001$ ) and latitude (coefficient $=0.744, P<0.001$ ). Moreover, through adjustment and discretization of HDI, we also observed that latitude (coefficient $=0.774, P<0.001$ ) exerts an independent effect on the prevalence of $H$. pylori infection.

Based on existing data, we conducted meta-analysis to analyze the influences of age, sex, smoking and education on the $H$. pylori infection rate. $H$. pylori-infected individuals were found to be significantly older than non-infected infected individuals (SMD $=0.26,95 \%$ $\mathrm{CI}=0.09-0.44, I^{2}=94.2 \%, P<0.01$; Additional file 1) and males were 1.1 times more likely to be infected with $H$. pylori than females $(\mathrm{OR}=1.1,95 \% \mathrm{CI}=1.04-$ 1.16, $\quad I^{2}=72.1 \%, \quad P<0.01$; Additional file 1 ). Furthermore, individuals with a high level of education were 0.58 times more likely to be infected with $H$. pylori than individuals with a low level of education $\left(\mathrm{OR}=0.58,95 \% \mathrm{CI}=0.41-0.84, I^{2}=97.1 \%\right.$, $P<0.01$; Additional file 1). In contrast, there were no significant differences in the $H$. pylori infection rates between smokers and non-smokers $(\mathrm{OR}=0.99,95 \% \mathrm{CI}=$ 0.93-1.05, $I^{2}=43.3 \%, P=0.042$; Additional file 1).

\section{Discussion}

To the best of our knowledge, this is the first study investigating the relationships between $H$. pylori infection and latitude, average annual temperature and average daily sunshine time. Our multiple-factor analysis showed that higher average annual temperature was associated with lower $H$. pylori infection rates, while average daily sunshine time correlated positively with $H$. pylori infection. HDI was also found to be a significant factor, with higher HDI associated with lower infection rates.

We found higher H. pylori infection rates among the populations in high latitude regions. Furthermore, we observed a trend of increasing infection rates with increasing latitude. Vitamin D is known to be closely linked to ultraviolet radiation exposure [22] and lower latitudes are characterized by stronger ultraviolet radiation. Therefore, people living in low latitude zones may generate higher levels of vitamin $\mathrm{D}$, which played a protective role in $H$. pylori infection, as shown by us previously [13]. In addition, Kwon et al. reported that vitamin D induced expression of vitamin D3-upregulated protein 1 (VDUP1), which reduced $H$. pylori-induced gastric carcinogenesis in mice [23]. The vitamin D nuclear receptor, which binds vitamin $\mathrm{D}$, is detected in gastric mucosa [24]. Furthermore, the function of vitamin $\mathrm{D}$ in antimicrobial innate immune responses [25] indicates the 
possibility of a role in reducing $H$. pylori infection. In general, it can be speculated that different latitudes affect the synthesis of vitamin $\mathrm{D}$, with a consequential influence on $H$. pylori infection rates. Our study also showed a suggestive correlation between latitude and infection rate, although no significant correlation was identified in our multiple-factor analysis. Interestingly, however, we observed that latitude independently affected $H$. pylori infection in Asian countries, indicating that latitude is an extremely important factor in $H$. pylori infection in these regions. Therefore, further studies are required to support the hypothesis that latitude influences $H$. pylori infection rates in different geographical regions.

In this study, we also found that average annual temperature was significantly related to $H$. pylori infection, a link that has not been reported previously. We propose that suitably warm temperatures provide more opportunities for people to engage in outside activities, with increased vitamin D synthesis resulting from the increased exposure to sunlight. However, this hypothesis requires verification in large-scale epidemiological studies and basic research.

Our results showed that more average daily sunshine time is associated with higher $H$. pylori infection rate, which was contrary to our expectation based on the positive correlation of daily sunshine time with vitamin D synthesis. Daily sunshine time is determined by several factors such as altitude, active area, environment. Our findings may provide evidence that ultraviolet light intensity based on latitude has a much more important influence on $H$. pylori infection than ultraviolet light exposure time. Furthermore, the $H$. pylori infection rate may also be influenced by other factors, such as sex, age, and education.

HDI, which represents the gold standard for measurement of human development, was found to be inversely related to $H$. pylori infection, which is consistent with a previous epidemiological study [26]. In our study, we found lower $H$. pylori infection rates in regions with latitude $>45^{\circ}$, which was not consistent with the trend of increasing $H$. pylori infection rates with latitude. Globally, regions higher than $45^{\circ}$ latitude contain mainly the developed countries of North America and Northern Europe; thus, indicating that HDI plays a predominant role in the lower H. pylori infection rates found in these regions. ANCOVA showed a linear relationship between HDI and latitude and that HDI had a distinct influence on the effect of latitude on $\mathrm{H}$. pylori infection rates. Furthermore, we observed the lowest infection rate among individuals living in developed regions with low latitude, which further illustrated that the importance of latitude and HDI on the rate of $H$. pylori infection.

Due to the lack of related reports, the results of our analysis of the influence of smoking were inconsistent with those of previous studies [27]; further investigations are required for clarification of the influence of this factor on the rate of $H$. pylori infection.

To our knowledge, this is the first study of the association of $H$. pylori infection with geographical latitude, average daily sunshine time, and average annual temperature.

Despite the strength of the numbers of participants, some limitations of our study should be noted. First, the studies included in our analysis predominantly used two diagnostic methods: the ${ }^{13} \mathrm{C}$ UBT and the serologic test; however, different diagnostic methods have different positive diagnostic rates [28]. The specificity and sensitivity of serologic tests were $100 \%$ and $82 \%$ respectively, while the corresponding values for the ${ }^{13} \mathrm{C}$ UBT were $100 \%$ and $92 \%$, respectively [29]. Therefore, the differences in diagnostic approach may lead directly to selection bias in the included participants and consequently, to a greatly increased false positive rate. The ${ }^{13} \mathrm{C}$ UBT is the most effective noninvasive diagnostic method for detection of $H$. pylori infection with high specificity and sensitivity that is currently available. Second, our definition of latitude, average daily sunshine time and average annual temperature were based on the areas in which the research originated, while it was not certain that the participants really represented the area selected. Selected participants originating from different areas introduce a selection bias. In addition, although all the participants were healthy and without any digestive diseases during the study, it was not clear whether previous disease or other systemic diseases may have influenced $H$. pylori infection. Finally, several original studies failed to adjust for potentially confounding factors such as race, environmental factor, and gene polymorphisms. Any of these factors can lead to bias in the results.

\section{Conclusions}

In conclusion, we have demonstrated that $H$. pylori infection is significantly related to average annual temperature, average daily sunshine time and HDI. Higher average annual temperature and HDI correlated with lower $H$. pylori infection rates. Average daily sunshine time correlated positively with $H$. pylori infection rates; however, no correlation between the prevalence of H. pylori infection and latitude was observed in the multivariate analysis. Nevertheless, individuals living in high latitude regions showed a high infection rate. In consideration of the influence of HDI, a suggestive increasing trend of $H$. pylori infection rate with rising latitude also existed. Moreover, the combined statistically significant differences in infection rates at different latitudes and HDI scores suggest that latitude is also an influencing factor. Therefore, populations living in regions 
with low average annual temperature, low HDI and high latitude need to be alerted to the risk of $H$. pylori infection. We also believe that the global prevalence of $H$. pylori infection should be evaluated from a human development perspective. Our findings require further verification in large-scale epidemiological investigations.

\section{Additional file}

Additional file 1: Meta-analysis of analyzing the influences of age, sex smoking and education on the H. pylori infection rate. H. pylori-infected individuals were older than non-infected infected individuals $(S M D=0.26$, $95 \% \mathrm{Cl}=0.09-0.44,12=94.2 \%, P<0.01)$ and males were 1.1 times more likely to be infected with $\mathrm{H}$. pylori than females $(\mathrm{OR}=1.1,95 \% \mathrm{Cl}=1.04-1.16$, $12=72.1 \%, P<0.01$ ). High-educated individuals were 0.58 times more likely to be infected with $H$. pylori than low-educated individuals $(\mathrm{OR}=0.58,95 \%$ $\mathrm{Cl}=0.41-0.84, \mathrm{I}=97.1 \%, P<0.01)$. There were no significant differences in the H. pylori infection rates between smokers and non-smokers $(\mathrm{OR}=0.99,95 \% \mathrm{Cl}=0.93-1.05,12=43.3 \%, P=0.042)$. (PDF $155 \mathrm{~kb})$

\section{Abbreviations}

H. pylori: Helicobacter pylori; HDI: Human development index; RUT: Rapid urease test; UBT: Urea breath test; VDR: Vitamin D receptor; VDUP1: Vitamin D3-upregulated protein 1

\section{Acknowledgments}

We thank Hong Zhang (Statistics expert, Institute of Biostatistics, Fudan School of Life Sciences) for his outstanding statistical methods assistance.

\section{Funding}

This study was funded by the National Natural Science Foundation of China (81400606) and the Science and Technology Plan Projects of Zhejiang Province, China (2015C33102).

\section{Availability of data and materials}

The datasets generated during and/or analyzed during the current study are available in the PubMed (https://www.ncbi.nlm.nih.gov/pubmed/),

ClinicalTrials.gov (https://clinicaltrials.gov/), EMBASE (https:// www.sciencedirect.com/) and Web of Science (https:// login.webofknowledge.com/) databases, or available from the corresponding author on reasonable request. In addition, data of annual average sunshine time and average annual temperature are available from the Hong Kong Observatory (http://gb.weather.gov.hk/contentc.htm). The HDI data (1990-2012) are available from the United Nations Development Programme website (http://hdr.undp.org/en/reports/).

\section{Authors' contributions}

$L C, X P$ and $Y C H$ designed the study; $L C$ and $Y Y$ performed the research; $L L$ collected and analyzed the data; LC gave statistical support; LC wrote the paper. All authors have read and approved the final manuscript.

\section{Competing interests}

The authors declare that they have no competing interests.

\section{Publisher's Note}

Springer Nature remains neutral with regard to jurisdictional claims in published maps and institutional affiliations.

\section{Author details}

'Department of Gastroenterology, the First Affiliated Hospital, College of Medicine, Zhejiang University, No. 79 Qingchun Road, Hangzhou 310003, China. ${ }^{2}$ Department of Rheumatology, the First Affiliated Hospital, College of Medicine, Zhejiang University, Hangzhou 310003, China.
Received: 23 November 2017 Accepted: 11 April 2018

Published online: 17 April 2018

\section{References}

1. Peek RM Jr, Blaser MJ. Pathophysiology of Helicobacter pylori-induced gastritis and peptic ulcer disease. Am J Med. 1997;102(2):200-7.

2. Eck M, Schmausser B, Haas R, Greiner A, Czub S, Muller-Hermelink HK. MALTtype lymphoma of the stomach is associated with Helicobacter pylori strains expressing the CagA protein. Gastroenterology. 1997;112(5):1482-6.

3. Huang JQ, Sridhar S, Chen Y, Hunt RH. Meta-analysis of the relationship between Helicobacter pylori seropositivity and gastric cancer. Gastroenterology. 1998;114(6):1169-79.

4. Konturek PC, Konturek SJ, Brzozowski T. Gastric cancer and Helicobacter pylori infection. J Physiol Pharmacol. 2006;57(Suppl 3):51-65.

5. Suerbaum S, Michetti P. Helicobacter pylori infection. N Engl J Med. 2002; 347(15):1175-86.

6. Cellini L. Helicobacter pylori: a chameleon-like approach to life. World J Gastroenterol. 2014;20(19):5575-82.

7. Yan TL, Hu QD, Zhang Q, Li YM, Liang TB. National rates of Helicobacter pylori recurrence are significantly and inversely correlated with human development index. Aliment Pharmacol Ther. 2013;37(10):963-8.

8. Chen TP, Hung HF, Chen MK, Lai HH, Hsu WF, Huang KC, et al. Helicobacter pylori infection is positively associated with metabolic syndrome in Taiwanese adults: a cross-sectional study. Helicobacter. 2015;20(3):184-91.

9. de Martel C, Parsonnet J. Helicobacter pylori infection and gender: a metaanalysis of population-based prevalence surveys. Dig Dis Sci. 2006;51(12): 2292-301.

10. Bures J, Kopacova M, Koupil I, Vorisek V, Rejchrt S, Beranek M, et al. Epidemiology of Helicobacter pylori infection in the Czech Republic. Helicobacter. 2006;11(1):56-65.

11. Calvet X, Ramirez Lazaro MJ, Lehours P, Megraud F. Diagnosis and epidemiology of Helicobacter pylori infection. Helicobacter. 2013;18(Suppl 1):5-11.

12. Fock KM, Ang TL. Epidemiology of Helicobacter pylori infection and gastric cancer in Asia. J Gastroenterol Hepatol. 2010;25(3):479-86.

13. Guo L, Chen W, Zhu H, Chen Y, Wan X, Yang N, et al. Helicobacter pylori induces increased expression of the vitamin $d$ receptor in immune responses. Helicobacter. 2014:19(1):37-47.

14. Bouillon R, Carmeliet $G$, Verlinden L, van Etten E, Verstuyf $A$, Luderer $H F$, et al. Vitamin $D$ and human health: lessons from vitamin $D$ receptor null mice. Endocr Rev. 2008;29(6):726-76.

15. Gascon-Barre M, Demers C, Mirshahi A, Neron S, Zalzal S, Nanci A. The normal liver harbors the vitamin $\mathrm{D}$ nuclear receptor in nonparenchymal and biliary epithelial cells. Hepatology (Baltimore, Md). 2003;37(5):1034-42.

16. Holick MF. Environmental factors that influence the cutaneous production of vitamin D. Am J Clin Nutr. 1995;61(3 Suppl):638S-45S.

17. von Elm E, Altman DG, Egger M, Pocock SJ, Gotzsche PC, Vandenbroucke JP. The strengthening the reporting of observational studies in epidemiology (STROBE) statement: guidelines for reporting observational studies. J Clin Epidemiol. 2008;61(4):344-9.

18. Malfertheiner P, Megraud F, O'Morain CA, Atherton J, Axon AT, Bazzoli F, et al. Management of Helicobacter pylori infection-the Maastricht IV/ Florence consensus report. Gut. 2012;61(5):646-64.

19. Szajewska H, Horvath A, Piwowarczyk A. Meta-analysis: the effects of Saccharomyces boulardii supplementation on Helicobacter pylori eradication rates and side effects during treatment. Aliment Pharmacol Ther 2010;32(9):1069-79.

20. Klugman J. The real wealth of nations: pathways to human development, 20th anniversary edn. New York: United Nations Development Programme; 2010.

21. Benjamini Y, Yekutieli D. The control of the false discovery rate in multiple testing under dependency. Ann Stat. 2001;29:1165-88.

22. Holick MF. Sunlight, ultraviolet radiation, vitamin D and skin cancer: how much sunlight do we need? Adv Exp Med Biol. 2014;810:1-16.

23. Kwon HJ, Won YS, Nam KT, Yoon YD, Jee H, Yoon WK, et al. Vitamin D(3) upregulated protein 1 deficiency promotes $\mathrm{N}$-methyl-N-nitrosourea and Helicobacter pylori-induced gastric carcinogenesis in mice. Gut. 2012;61 (1):53-63.

24. Trowbridge R, Mittal SK, Sharma P, Hunter WJ, Agrawal DK. Vitamin D receptor expression in the mucosal tissue at the gastroesophageal junction. Exp Mol Pathol. 2012;93(2):246-9.

25. Wang $T$, Nestel FP, Bourdeau V, Nagai Y, Wang Q, Liao J, et al. Cutting edge: 1,25-dihydroxyvitamin D3 is a direct inducer of antimicrobial peptide gene expression. J Immunol (Baltimore, Md : 1950). 2004;173(5):2909-12. 
26. Malaty HM. Epidemiology of Helicobacter pylori infection. Best Pract Res Clin Gastroenterol. 2007;21(2):205-14.

27. Santibanez M, Aguirre E, Belda S, Aragones N, Saez J, Rodriguez JC, et al. Relationship between tobacco, cagA and vacA 11 virulence factors and bacterial load in patients infected by Helicobacter pylori. PLoS One. 2015; 10(3):e0120444.

28. Dunn BE, Cohen H, Blaser MJ. Helicobacter pylori. Clin Microbiol Rev. 1997; 10(4):720-41.

29. Logan RP, Polson RJ, Misiewicz JJ, Rao G, Karim NQ, Newell D, et al. Simplified single sample 13Carbon urea breath test for Helicobacter pylori: comparison with histology, culture, and ELISA serology. Gut. 1991;32(12): $1461-4$

Ready to submit your research? Choose BMC and benefit from:

- fast, convenient online submission

- thorough peer review by experienced researchers in your field

- rapid publication on acceptance

- support for research data, including large and complex data types

- gold Open Access which fosters wider collaboration and increased citations

- maximum visibility for your research: over $100 \mathrm{M}$ website views per year 